\title{
Knowledge and attitude towards emergency contraception in females of urban area of Lucknow, Uttar Pradesh, India
}

\author{
Malvika Mishra ${ }^{1}$, Shiv Shanker Tripathi ${ }^{2}$, Manish Kumar Verma ${ }^{3}$
}

\author{
${ }^{1}$ Department of Obstetrics and Gynecology, Shri Ram Murti Smarak Institute of Medical Sciences, Bareilly, Uttar \\ Pradesh, India \\ ${ }^{2}$ Department of Emergency Medicine, Dr Ram Manohar Lohia Institute of Medical Sciences Lucknow, Uttar Pradesh, \\ India \\ ${ }^{3}$ Department of Biochemistry, Career Institute of Medical Sciences and Hospital, Lucknow, Uttar Pradesh, India
}

Received: 29 October 2016

Revised: 02 November 2016

Accepted: 30 November 2016

*Correspondence:

Dr. Shiv Shanker Tripathi,

E-mail: shiv_shanker2@rediffmail.com

Copyright: (c) the author(s), publisher and licensee Medip Academy. This is an open-access article distributed under the terms of the Creative Commons Attribution Non-Commercial License, which permits unrestricted non-commercial use, distribution, and reproduction in any medium, provided the original work is properly cited.

\section{ABSTRACT}

Background: Emergency contraception are birth control measures that, if taken after unprotected sexual intercourse, contraceptive failure, incorrect use of contraceptives or in cases of sexual assault may prevent pregnancy. The aim of the study was to assess the knowledge and attitude of female living in urban part of Lucknow district from September 2015 to August 2016.

Methods: This was a descriptive, cross-sectional study conducted at RML Hospital, Lucknow from September 2015 to August 2016. A cross sectional study design was conducted and Participants were selected using simple random sampling method. Data was collected by using self-administered questionnaires. Data processing and analysis: The collected data was entered into a computer and analyzed using statistical package of social science version 20.0.

Results: In this study it was found that, Out of 385 subjects 54\% (209) new the correct time interval for EC to be effective and 91\% (350) new that this is for prevention of unplanned pregnancy. Out of 385 subjects $77 \%$ (345) reported that they had heard the word EC from different sources, however 23\% (90) reported that they never heard about that it means that still there is a scope of health awareness activities and health education to improve the knowledge of EC. Different attitudes of females towards emergency contraception some different pair of questions was asked. Out of 385 subjects $85 \%$ (329) were reported that they have positive attitudes in terms of benefits of EC to reduce the risk of unplanned pregnancy. A few number of subjects i.e. $12 \%$ (48) reported negative attitudes towards EC where as $3 \%(8)$ did not respond. The more than half subjects i.e. 68\% (260) reported that they use EC even if their partners disagreed with them where as $11 \%$ (41). Cultural belief was found as an barrier in having negative attitudes towards EC. The Religion, Occupation and educational status affect knowledge and attitudes towards EC.

Conclusions: The results show that there is a scope of health awareness activities and health education to improve the knowledge and attitude towards EC.

Keywords: Awareness, Attitude, Emergency contraception, Public health issue

\section{INTRODUCTION}

Unintended pregnancy continues to be a major public health issue in the India. Emergency contraception (EC) describes the use of contraceptive measures to prevent pregnancy occurring after intercourse has taken place. Emergency contraception is birth control that prevents pregnancy after sex, that's why it is also called "the morning after pill" the day after pill or morning after contraception and generally there are two types of contraception .Emergency contraceptive pills (ECPs) and Intrauterine device (IUD). Across the world, some additional methods are being used in EC. In addition to progestin only and combined methods, ulipristal acetate 
has been approved as an ECP in Europe in early 2009 and in the US in August 2010, whereas mifepristone is generally used as either EC or as an abortifacient in Russia and China. Emergency contraception (EC) refers to methods that women can use to prevent pregnancy after unprotected sexual intercourse, and is also known as "post-coital"contraception. ${ }^{1,3}$ Situations of unprotected intercourse where EC can be used as a backup contraceptive method include, failure of barrier methods such as slippage, breakage or misuse of the condom, sexual assaults, rape, failed coitus interruptus, two or more consecutive missed oral contraceptive pills, or simply because intercourse was unexpected and therefore contraception had not been used. ${ }^{2}$ Worldwide unplanned pregnancy is a major medical, social, and public health problem. ${ }^{3}$ There are 80 million unplanned pregnancies in the world every year, of which $38 \%$ of all pregnancies can be deemed an epidemic. ${ }^{4}$ The WHO estimates that about 46 million abortions are performed under unsafe conditions. ${ }^{5}$ There is growing worldwide acceptance and promotion of EC as a measure to reduce the level of unwanted pregnancies and, hence, unsafe abortion. In an American study, it was reported that nearly half of all pregnancies were unintended and half of these pregnancies end in elective termination. ${ }^{6}$ Another study highlighted the potential effect of EC in this regard could be most evident in sub-Saharan Africa. ${ }^{7}$ Women in low income and minority groups are at highest risk of unintended have limited access to primary care and may have difficulty accessing highly effective contraception. ${ }^{8}$ As per the World Health Organization estimates, 210 million pregnancies occur annually, out of which, $38 \%$ are unwanted and $22 \%$ end up with abortion worldwide. In India, about 11 million abortions take place annually and around 20,000 women die every year due to abortionrelated complications. It was reported from a Nigerian study that EC could play an important role in averting pregnancies attributable to non-use or incorrect use of contraceptives, contraceptive failure, lack of knowledge about, or access to methods, or coerced sex. ${ }^{2}$

The National Health Policy 2000 states the achievement of reduction of Maternal Mortality Ratio by three fourths and achieving Replacement Fertility levels by 2010 as two of its goals. The Government of India introduced Emergency Contraceptive Pills (ECP) in the National Family Welfare Programmes in 2003 as one of the strategies to prevent unwanted pregnancies. Unsafe abortions are still a leading cause of maternal mortality, nearly $8 \%$ of the total, and also a major contributor to maternal morbidity. Government of India approved the dedicated regimen of emergency contraceptives in year 2001 and the same was introduced in the National Family Health Welfare Program in 2003. ${ }^{5}$ It was approval as over the counter for adults aged 18 and above by the Government of India in 2005.Prevention of an unwanted pregnancy through methods of Emergency Contraception will help to reduce the number of maternal deaths from unsafe abortions and also to reduce the fertility levels. However, there should be simultaneous realization of the fact that the real success of this service is to promote the acceptance of a regular contraceptive to prevent future pregnancies. Present document updates the information included in an earlier Guideline by the MoHFW in year 2003. Since then, EC pills have been made available through network of health care delivery institutions in public sector. Similarly, several dedicated products are available in commercial markets.

\section{Objectives}

\section{General objective}

To assess the knowledge and attitude of emergency contraception among females belong to urban area of Lucknow, from Sep 2015 to August 2016.

\section{Specific objectives}

- To assess the knowledge on emergency contraception among females belong to urban area of Lucknow, from Sep 2015 to August 2016.

- To identify the attitude towards emergency contraception among females belong to urban area of Lucknow, from Sep 2015 to August 2016.

\section{METHODS}

This was a descriptive, cross-sectional study conducted at RML Hospital, Lucknow from September 2015 to August 2016. The study was approved by the Institutional Ethics Committee. The study was conducted using pre-validated and pretested questionnaire. The sample size was calculated by using formula $n=4 p q / d^{2}$. Due to proper lack of study in nearby area to find rough value of $p$, it was taken as $50 \%$. By using this formula the minimum sample size was required as 385.The simple random sampling was used for data collection. The questionnaire included multiple choice questions, closed-ended and a few open-ended questions. Questionnaire was both in English and Hindi languages. The questionnaire elicited details on knowledge, attitude and practice toward the use of ECPs. It also included information on various socio demographic variables, such as age, sex, educational status, and marital status.

\section{Inclusion criterion}

All females visiting at OPD of Obstetrics and Gynecology at RML Hospital, Lucknow

- Age more than 18 years and less than 45 years

- Willing to participate in the study

\section{Exclusion criterion}

- Participants of age less than 18years and more than 45 years

- $\quad$ Suffering from any mental or psychological disease 
- Not willing to participate in the study

\section{Dependent variables}

- Knowledge on emergency contraception

- Attitude on emergency contraception

- Practice on emergency contraception

\section{Independent variables}

- Socio demographic variables

- Sexual and reproductive health behavior

- $\quad$ Exposed to media

\section{Data collection and analysis}

The questionnaire was bilingual and those who could not read and write, investigator filled the questionnaire. The information collected from the study subjects were captured in Microsoft excel and analysed by Statistical Packages for Social Sciences (SPSS) of version 20.0. Mean and SD while frequency and percentage were obtained for categorical data.

\section{RESULTS}

Table 1 shows the socio demographic details of study subjects. The age group of the study subjects was classified in four group's i.e.18-24, 25-31, 33-38 and 3945 years having the number of study subjects $90,86,99$ and 110. Out of 385 subjects $53 \%$ (205) were Hindu, $32 \%$ (125) were Muslims, $13 \%$ (50) were Christian and $1 \%$ (5) were others. The education level of $48 \%$ (186) was below high school, $52 \%$ (199) were above high school. The majority females were housewives i.e.79\% (305). 78\% (301) study subjects were married.

\section{Knowledge towards emergency contraception}

The knowledge towards emergency contraception is important component to be studied in community. In the present study four major information's were captured to get level of knowledge towards EC. Out of 385 subjects $54 \%$ (209) knew the correct time interval for EC to be effective and $91 \%$ (350) knew that this is for prevention of unplanned pregnancy. Out of 385 subjects $77 \%$ (345) reported that they had heard the word EC from different sources, however $23 \%$ (90) reported that they never heard about that. The majority of females, $73 \%$ (281) felt that they used EC before.

\section{Attitude towards emergency contraception}

To see the different attitudes of females towards emergency contraception some different pair of questions was asked. Out of 385 subjects $85 \%$ (329) were reported that they have positive attitudes in terms of benefits of EC to reduce the risk of unplanned pregnancy. A few number of subjects i.e. $12 \%$ (48) reported negative attitudes towards EC where as 3\% (8) did not respond. The more than half subjects i.e. 68\% (260) reported that they use EC even if their partners disagreed with them where as $11 \%$ (41) reported that they do not use if partners do not want collectively and $22 \%$ did not reply about that. When it tried to know whether there is any cultural barrier is there or not regarding emergency contraception, $31 \%$ (118) reported that they have some cultural beliefs regarding EC.

Table 1: Personal characteristics of study subjects.

\begin{tabular}{|c|c|c|}
\hline Variables & Frequency & $\%$ \\
\hline \multicolumn{3}{|l|}{ Age group } \\
\hline $18-24$ & 90 & 23 \\
\hline $25-31$ & 86 & 22 \\
\hline $32-38$ & 99 & 26 \\
\hline $39-45$ & 110 & 29 \\
\hline \multicolumn{3}{|l|}{ Religion } \\
\hline Hindu & 205 & 53 \\
\hline Muslim & 125 & 32 \\
\hline Christian & 50 & 13 \\
\hline Others & 5 & 1 \\
\hline \multicolumn{3}{|l|}{ Education } \\
\hline Below high school & 186 & 48 \\
\hline $\begin{array}{l}\text { High school to } \\
\text { Graduation }\end{array}$ & 134 & 35 \\
\hline $\begin{array}{l}\text { Graduation and above } \\
\text { /Professional }\end{array}$ & 65 & 17 \\
\hline \multicolumn{3}{|l|}{ Occupation } \\
\hline House wife & 305 & 79 \\
\hline Service & 21 & 5 \\
\hline Business & 9 & 2 \\
\hline Student & 40 & 10 \\
\hline Others & 10 & 3 \\
\hline \multicolumn{3}{|l|}{ Marital status } \\
\hline Married & 302 & 78 \\
\hline Unmarried & 65 & 17 \\
\hline Others & 18 & 5 \\
\hline
\end{tabular}

\section{DISCUSSION}

The actual studies, participants out of 385 subjects $85 \%$ (329) were reported that they have positive attitudes in terms of benefits of EC to reduce the risk of unplanned pregnancy. A few number of subjects i.e. $12 \%$ (48) reported negative attitudes towards EC where as $3 \%$ (8) did not respond. The more than half subjects i.e. $68 \%$ (260) reported that they use EC even if their partners disagreed with them where as $11 \%$ (41).

Cultural belief was found as a barrier in having negative attitudes towards EC. The Religion, Occupation and educational status affect knowledge and attitudes towards EC. 
Table 2: Knowledge towards emergency contraception.

\begin{tabular}{|lll|}
\hline $\begin{array}{l}\text { Knowledge } \\
\text { regarding EC }\end{array}$ & N & $\%$ \\
\hline $\begin{array}{l}\text { Correct time interval } \\
\text { for EC to be effective }\end{array}$ & 209 & 54 \\
\hline $\begin{array}{l}\text { Reason to use EC } \\
\text { (Prevent unplanned } \\
\text { pregnancy) }\end{array}$ & 350 & 91 \\
\hline Heard about EC & 34 & \\
\hline From TV & 26 & 9 \\
\hline From Newspaper & 117 & 7 \\
\hline $\begin{array}{l}\text { From Mother, sister, } \\
\text { Friends }\end{array}$ & 78 & 30 \\
\hline From sexual partner & 70 & 20 \\
\hline Others & 90 & 10 \\
\hline Never Heard & 281 & 23 \\
\hline Used EC before & 73 \\
\hline
\end{tabular}

Table 3: Attitude of study subjects towards emergency contraception.

\begin{tabular}{|c|c|c|}
\hline \multicolumn{3}{|l|}{ Attitude } \\
\hline $\begin{array}{l}\text { Positive attitude } \\
\text { (Benefits of using EC } \\
\text { outweigh the risk of } \\
\text { having an unplanned } \\
\text { pregnancy) }\end{array}$ & 329 & 85 \\
\hline $\begin{array}{l}\text { Negative attitude (the } \\
\text { use of EC did not } \\
\text { outweigh the risk of } \\
\text { having an unplanned } \\
\text { pregnancy) }\end{array}$ & 48 & 12 \\
\hline Did not respond & 8 & 3 \\
\hline \multicolumn{3}{|c|}{ Partner agreement regarding the use of EC } \\
\hline $\begin{array}{l}\text { Would use EC even if } \\
\text { their partners disagreed } \\
\text { with them (Yes) }\end{array}$ & 260 & 68 \\
\hline $\begin{array}{l}\text { Would discontinue } \\
\text { the use of EC }\end{array}$ & 23 & 6 \\
\hline $\begin{array}{l}\text { If their partners } \\
\text { dislike the use of EC }\end{array}$ & 18 & 5 \\
\hline Did not respond & 84 & 22 \\
\hline \multicolumn{3}{|c|}{ Cultural belief or religion as barriers } \\
\hline Yes & 118 & 31 \\
\hline No & 267 & 69 \\
\hline
\end{tabular}

In this study, sexually active participants had a superior attitude than sexually inactive participants, who are believed to be reluctant about EC. In this study one important aspect we need to give awareness to, is the presence of sexual abuse; reported that the reason for their unintended pregnancy was due to forced sexual intercourse. It is unspecified that the findings of this study can be generalized because of the representative nature of study participants (random sampling) and adequate number of sample size. Although the questionnaire contained some socially sensitive questions, in order to obtain a reliable data, respondents were well informed about the purpose of the study and they were reassured about confidentiality and anonymity. Conducting the study among these study participants who are relatively in higher educational level is novel about the study since this is a good opportunity to illuminate the influence of education in awareness of EC. ${ }^{12-15}$

Table 4: Association of different variables on knowledge, attitude and practice of EC*.

\begin{tabular}{|lll|}
\hline Variable & Knowledge & Attitude \\
\hline Age group & $\begin{array}{l}\text { Chi square } \\
=1.99, \mathrm{p}=0.34\end{array}$ & $\begin{array}{l}\text { Chi square } \\
=1.09, \mathrm{p}=0.54\end{array}$ \\
\hline Religion & $\begin{array}{l}\text { Chi square } \\
=9.22, \mathrm{p}=0.0007\end{array}$ & $\begin{array}{l}\text { Chi square } \\
=8.08, \mathrm{p}=0.004\end{array}$ \\
\hline Education & $\begin{array}{l}\text { Chi square } \\
=11.39, \mathrm{p}=0.0004\end{array}$ & $\begin{array}{l}\text { Chi square } \\
=17.70, \mathrm{p}=0.0001\end{array}$ \\
\hline Occupation & $\begin{array}{l}\text { Chi square } \\
=16.89, \mathrm{p}=0.00001\end{array}$ & $\begin{array}{l}\text { Chi square } \\
=31.21, \mathrm{p}=0.0001\end{array}$ \\
\hline
\end{tabular}

*After assessing an interview each subjects was reported as aware/not aware, positive attitude/negative attitude on EC.

\section{CONCLUSION}

The mean age of study subjects was $32.33( \pm 9.20)$ years. In the present paper significant conclusion are out of 385 subjects 54\% (209) knew the correct time interval for EC to be effective and $91 \%$ (350) knew that this is for prevention of unplanned pregnancy. Out of 385 subjects $77 \%$ (345) reported that they had heard the word EC from different sources, however $23 \%$ (90) reported that they never heard about that it means that still there is a scope of health awareness activities and health education to improve the knowledge of EC.

The attitudes of females living in urban part of area still have unsatisfactory attitudes towards EC so some solid actions should be implemented to change the negative attitude.

Age group is not associated with awareness level and attitude whereas religion, educational status and occupation has association with awareness and attitude $(\mathrm{p}<0.05)$ so by improving educational status, by community based health education and by reducing unemployment awareness and attitude can be changed.

\section{Funding: No funding sources}

Conflict of interest: None declared

Ethical approval: The study was approved by the Institutional Ethics Committee

\section{REFERENCES}

1. Trussell J, Koenig J, Ellertson C, Stewart F. Preventing unintended pregnancy: The costeffectiveness of three methods of emergency contraception. Am J Public Health. 1997;87:932-7. 
2. WHO. Emergency Contraception - World Health Organization. [Last accessed on 2015 Oct 10]. Available from: http://www.who.int/mediacentre/factsheets/fs244/en.

3. Mittal S. Emergency contraception-potential for women's health. Indian J Med Res. 2014;140(Suppl(1):S45-52.

4. Tolossa E, Meshesha B, Abajobir AA. Assessment of level of knowledge and utilization of emergency contraception among female students of Hawassa University, South Ethiopia. Adv Reprod Sci. 2013;1:51-6.

5. Saikia H, Lama A. OTC - Availability of emergency contraceptive Levonorgestrel: A review. J Pharm Res. 2011;4:67-71.

6. Rahaman H, Renjhen P, Kumar A, Pattanshetty S, Sagir A, Dubey H. A study on emergency contraceptive practice among nursing staff in Sikkim, India - A cross sectional study. AMJ. 2010;3:667-71.

7. Renjhen P, Kumar A, Pattanshetty S, Sagir A, Samarasinghe CM. A study on knowledge, attitude and practice of contraception among college students in Sikkim, India. J Turk Ger Gynecol Assoc. 2010;11:78-81.

8. Raina S. Assessment of knowledge, attitude, and practice in health care delivery. N Am J Med Sci. 2013;5:249-50.
9. Steyn PS, Mason D. Emergency contraception: a review. O and G Forum. 2009;19:127-33.

10. Olufunke ME, Osaretin E, Victor I. Health care providers' knowledge of, attitudes toward and provision of emergency contraception in Lagos, Nigeria. Intl Fam Plann Perspect. 2006;32:89-93.

11. Kang HS, Moneyham L. Use of emergency contraceptive pills and condoms by college students: a survey. Int J Nurs Stud. 2008;45:775-83.

12. WHO/Division of Reproductive Health. Unsafe abortion. Global and regional estimates of incidence of and mortality due to unsafe abortion, with a listing of available country data (WHO/RHT/MSM/97.16) Geneva, Switzerland. World Health Organization (WHO), 1998.

13. Wallace JL, Weinstein J, Wu J. Emergency contraception: knowledge and attitudes of family medicine providers. Fam Med. 2004;36:417-22.

14. Baiden F, Awini E, Clerk C. Perceptions of university students in Ghana about emergency contraception. Contraception. 2002;66:23-6.

15. Schwarz EB, Gerbert B, Gonzales R. Need for emergency contraception in urgent care settings. Contraception. 2007;75:285-8.

16. Guidelines for Administration of Emergency Contraceptive Pills by Health Care Providers Family Planning Division Ministry of Health and Family Welfare Government of India. 2008. pp. 3-23.

Cite this article as: Mishra M, Tripathi SS, Verma MK. Knowledge and attitude towards emergency contraception in females of urban area of Lucknow, Uttar Pradesh, India. Int J Reprod Contracept Obstet Gynecol 2017;6:210-4. 